\section{Porin: A New Button Mushroom (Agaricus bisporus) Allergen}

Betancor $\mathrm{D}^{1,2 *}$, Nuñez-Borque $\mathrm{E}^{3 *}$, Cuesta-Herranz $\mathrm{J}^{2,6}$, Escudero $\mathrm{C}^{4,6 *}$, Freundt $\mathrm{N}^{5}$, Pastor-Vargas $\mathrm{C}^{3,6 *}$, Ibañez $\mathrm{MD}^{4,6}$ ${ }^{1}$ Allergy Department, Hospital Universitario Niño Jesús, Madrid, Spain

${ }^{2}$ Allergy Department, Hospital Universitario Fundación Jiménez Diaz, Madrid, Spain

${ }^{3}$ Department of Allergy and Immunology, FIIS-Fundación Jiménez Díaz, UAM, Madrid,Spain

${ }^{4}$ Allergy Department, Hospital Infantil Universitario Niño Jesús, Madrid, Spain

${ }^{5}$ Allergy Department, Hospital Clínico San Carlos, Madrid, Spain ${ }^{6}$ RETIC ARADyAL, Instituto de Salud Carlos III, Spain

*These authors contributed equally to the manuscript.

J Investig Allergol Clin Immunol 2020; Vol. 30(2): 135-136 doi: $10.18176 /$ jiaci.0454

Key words: Allergy to mushroom. Button mushroom allergen. Porin.

Palabras clave: Alergia al champiñón. Alérgenos del champiñón común. Porinas.

White or button mushroom (Agaricus bisporus) is a fungus belonging to the Agaricaceae family [1]. It is the most widely cultivated species of fungus in the world, especially in North America and Europe [1]. Allergy to mushroom is very infrequent, and few allergens have been documented [2]. We report the identification of a new button mushroom allergen.
A 15-year-old girl reported an episode of generalized urticaria, abdominal pain, and vomiting 15 minutes after eating mushroom lasagna. She received oral antihistamine treatment, and her symptoms resolved 1 hour later. She had a personal history of atopic dermatitis, fish allergy, and allergic rhinitis and asthma due to pollens. She was also sensitized to mold, although this was not clinically relevant.

Skin prick testing (SPT) to a battery of common aeroallergens (ALK, Spain) was positive to Lollium species $(7 \times 5 \mathrm{~mm})$ and molds (Alternaria alternata, $8 \times 4 \mathrm{~mm}$; Aspergillus fumigatus, $5 \times 3 \mathrm{~mm}$; and Cladosporium herbarum, $3 \times 3 \mathrm{~mm}$ ) and negative to other pollens, dust mites, and animal dander. Skin prick testing with purified allergens was negative for Pho d 2 (profilin) (ALK, Spain) and peach lipid transfer protein (Bial-Aristegui, Spain). Prick-by-prick testing with different parts of a raw button mushroom was positive to the stem $(11 \times 10 \mathrm{~mm})$, cap $(7 \times 5 \mathrm{~mm})$, and gill $(6 \times 3 \mathrm{~mm})$.

Total IgE determination by the ImmunoCAP technique (Thermo Fisher Scientific) revealed a value of $400 \mathrm{kU} / \mathrm{L}$. Specific IgE to mushroom was $0.27 \mathrm{kU} / \mathrm{L}$.

Two button mushroom extracts were prepared from raw and cooked $A$ bisporus to perform SDS-PAGE. Briefly, $200 \mathrm{~g}$ of button mushroom was homogenized in $100 \mathrm{~mL}$ of acetone at $-60^{\circ} \mathrm{C}$ and stored overnight at $-80^{\circ} \mathrm{C}$. The sample was centrifuged at $4500 \mathrm{~g}$ for 15 minutes at $40^{\circ} \mathrm{C}$. The pellet was then washed 3 times with acetone at $-60^{\circ} \mathrm{C}$, lyophilized, dissolved in phosphate-buffered saline, and extracted overnight at $4^{\circ} \mathrm{C}$ under constant magnetic stirring. After centrifugation at $14000 \mathrm{~g}$ for 45 minutes at $4^{\circ} \mathrm{C}$, the supernatant was dialyzed against $\mathrm{NH}_{4} \mathrm{HCO}_{3}$ $0.1 \mathrm{M}$, lyophilized, and dissolved in phosphate-buffered saline. For in vitro experiments, the protein concentration of the button mushroom extract was adjusted to $1 \mathrm{mg} / \mathrm{mL}$.

SDS-PAGE of cooked button mushroom extract revealed multiple protein bands with molecular weights ranging from
A

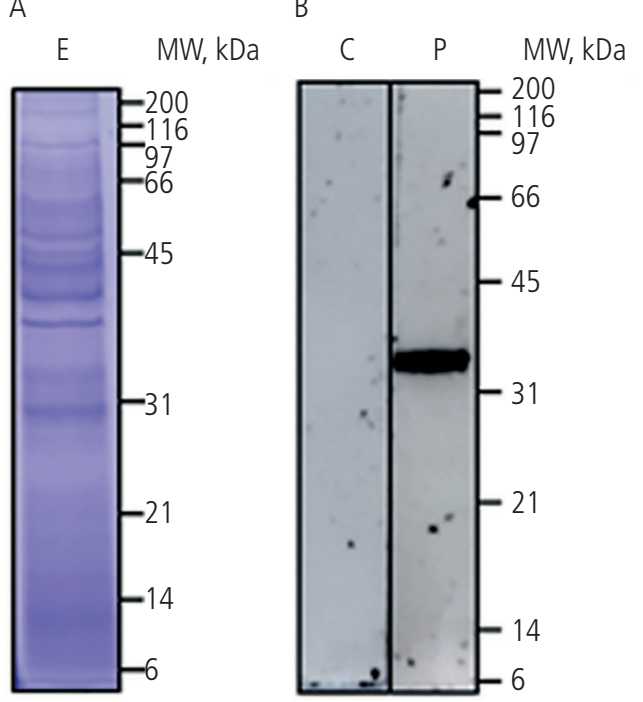

C

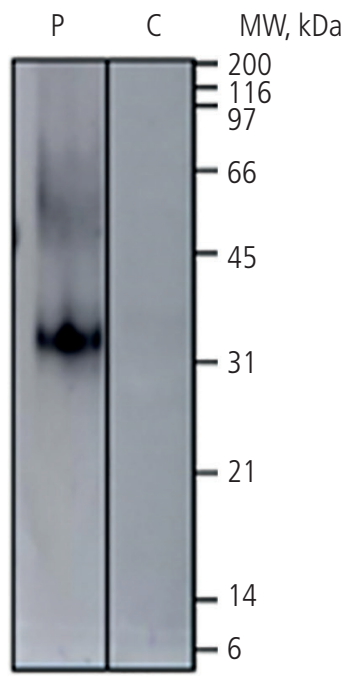

D

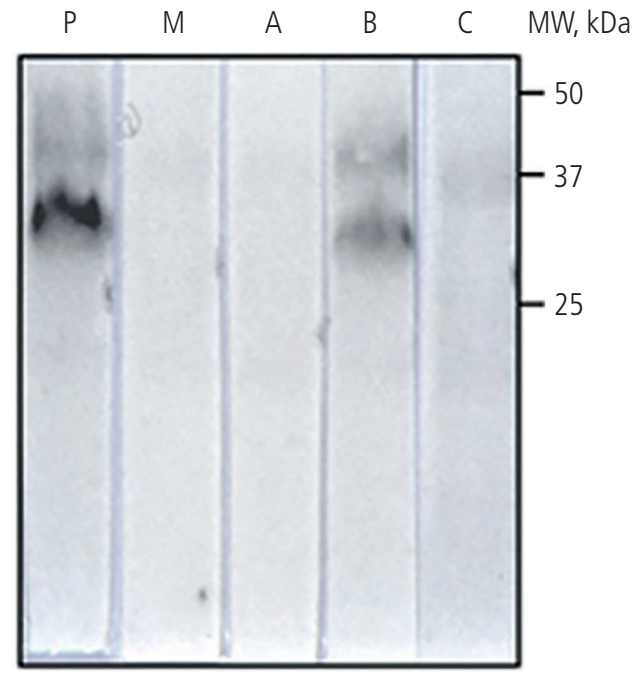

Figure. A, SDS-PAGE with boiled button mushroom extract. B, SDS-PAGE IgE-immunoblotting of boiled extract with patients' serum. C, SDS-PAGE IgEimmunoblotting of raw button mushroom extract. D, Immunoblotting-inhibition with Alternaria alternata. MW indicates molecular weight; $E$, boiled white mushroom extract; $C$, negative control (nonatopic individual) serum; $P$, patient serum; $M$, patient's serum preincubated with button mushroom as inhibitor (positive control of inhibition); $A$, patient's serum preincubated with Alternaria alternata extract; $B$, patient's serum preincubated with bovine serum albumin (negative control of inhibition). 
6 to $200 \mathrm{kDa}$ (Figure, A). Immunoblotting assays with the patients' serum revealed an IgE-binding band with an apparent molecular weight of $36 \mathrm{kDa}$ (Figure, B). Immunoblotting of raw button mushroom revealed a similar IgE-binding band of around $36 \mathrm{kDa}$ (Figure, C).

A $36-\mathrm{kDa}$ protein band recognized by the patient's serum was extracted from the gel. Protein was identified by mass spectrometry, as previously reported [3], as well as by searching a nonredundant protein sequence database (NCBI) using the Mascot program (http://www.matrixscience.com) in the Proteomic Service of Complutense University of Madrid, which is a member of the ProteoRed Network. The search revealed 1 peptide with the sequence QALVQQGSVAGR; subsequent research in protein databases demonstrated that the sequence corresponded to a porin.

The patient's serum was preincubated overnight at $4^{\circ} \mathrm{C}$ with button mushroom extract (positive inhibition control), A alternata extract (Bial-Aristegui, Spain), and bovine serum albumin (negative inhibition control). Immunoblotting-inhibition revealed that this $36-\mathrm{kDa}$ IgE band was inhibited both by button mushroom extract and by A alternata extract (Figure, D).

Allergy to mushroom is uncommon; however, some species, such as shiitake mushroom, have been investigated in depth owing to their allergenicity [4,5], and while some button mushroom allergens have been documented, not all of them have been identified.

Thermolabile button mushroom proteins of about 43 and $67 \mathrm{kDa}$ [6] have been identified in raw mushroom extract but not in cooked extract. In the case we report, a button mushroom protein of about $36 \mathrm{kDa}$ was demonstrated in both extracts (raw and cooked). Two button mushroom proteins of $15.8 \mathrm{kDa}$ and $14.3 \mathrm{kDa}$ have been identified as occupational allergens [7], although the patient in the present report had no allergic symptoms associated with contact with molds. Herrera-Mozo et al [8] identified a cross-reactive protein of about $30 \mathrm{kDa}$ in mushroom and spinach; however, this was not sequenced. In the present case, the patient had eaten spinach in the past without symptoms.

IgE-mediated bands have been identified with $A$ bisporus extract [2]. Sequencing showed these 2 thermostable proteins to be a $24-\mathrm{kDa}$ manganese-dependent superoxide dismutase (MnSOD) and a 27-kDa NADP-dependent mannitol dehydrogenase. In the present case, we found a $36-\mathrm{kDa} \mathrm{IgE}-$ binding band, which proved to be a porin.

The presence of IgE cross-reactivity between proteins from mushrooms and molds has been demonstrated [2,6,7]. This is the first report of a porin being identified as a mold allergen; in the present case, it was identified as an allergen of $A$ alternata.

Porins are a large family of proteins involved in the passive transport of small hydrophilic molecules through the membrane. They also participate in nuclear transport and in preventing accumulation of toxins [9]. Their structure takes the form of a cylinder formed by amphipathic $\beta$-barrels with a hydrophilic interior and a hydrophobic exterior. Porins have been described mostly in the external membrane of bacteria, although they have also been found in the membrane of mitochondria and chloroplasts. Mitochondrial porins have been found in all eukaryotic cells and have molecular masses of around $30 \mathrm{kDa}[10]$. Furthermore, porins have been reported to be the allergen in yellow fever mosquito
(Aedes aegypti [Aed a 6]) and southern house mosquito (Culex quinquefasciatus [Cul q 6]).

We report a new 36-kDa allergen from button mushroom (A bisporus) and from a mold (A alternata). The allergen was identified as a member of the porin family. To our knowledge, this is the first time a porin has been identified as both a food allergen and an aeroallergen. More studies are needed to fully characterize this allergen family.

\section{Funding}

This work was supported by the Thematic Network and Co-operative Research: ARAdyAL (RD16/0006/0013 and RD16/0006/0026).

\section{Conflicts of Interest}

The authors declare that they have no conflicts of interest.

\section{References}

1. McGee CF. Microbial ecology of the Agaricus bisporus mushroom cropping process. Appl Microbiol Biotechnol. 2018;102(3):1075-83.

2. Gabriel MF, González-Delgado P, Postigo I, Fernández J, Soriano V, Cueva B, et al. From respiratory sensitization to food allergy: Anaphylactic reaction after ingestion of mushrooms (Agaricus bisporus). Med Mycol Case Rep. 2015;8:14-6.

3. Pastor C, Cuesta-Herranz J, Cases B, Pérez-Gordo M, Figueredo $E$, de las Heras $M$, et al. Identification of major allergens in watermelon. Int Arch Allergy Immunol. 2009;149:289-90.

4. Pravettoni V, Primavesi L, Piantanida M. Shiitake mushroom (Lentinus edodes): a poorly known allergen in Western countries responsible for severe work-related asthma. Int J Occup Med Environ Health. 2014;27(5):871-4

5. Senti $G$, Leser $C$, Lundberg $M$, Wüthrich B. Allergic asthma to shiitake and oyster mushroom. Allergy. 2000;55(10):975-6.

6. Dauby PA, Whisman BA, Hagan L. Cross-reactivity between raw mushroom and molds in a patient with oral allergy syndrome. Ann Allergy Asthma Immunol. 2002;89(3):319-21.

7. Venturini M, Lobera T, Blasco A, Del Pozo MD, González I, Bartolomé B. Occupational asthma caused by white mushroom. J Investig Allergol Clin Immunol. 2005;15(3):219-21.

8. Herrera-Mozo I, Ferrer B, Luís Rodriguez-Sanchez J, Juarez C. Description of a novel panallergen of cross-reactivity between moulds and foods. Immunol Invest. 2006;35(2):181-97.

9. Pawłowicza I, Masajada K. Aquaporins as a link between water relations and photosynthetic pathway in abiotic stress tolerance in plants. Gene. 2019;687:166-72.

10. Benz R. Permeation of hydrophilic solutes through mitochondrial outer membranes: review on mitochondrial porins. Biochimica et Biophysica Acta. 1994;1197(2):167-96.

- Manuscript received July 2, 2019; accepted for publication September 10, 2019.

Diana Betancor E-mail: Diana.betancor@quironsalud.es 